\title{
Sensitivity and specificity of the abbreviated profile of hearing aid benefit (APHAB)
}

\author{
Jan Löhler ${ }^{1,2,3,4}$ • $~ F$. Gräbner ${ }^{3,4} \cdot$ B. Wollenberg ${ }^{3,4} \cdot$ P. Schlattmann ${ }^{5} \cdot$ \\ R. Schönweiler ${ }^{6,7}$
}

Received: 4 April 2017 / Accepted: 19 July 2017 / Published online: 29 July 2017

(c) The Author(s) 2017. This article is an open access publication

\begin{abstract}
Subjective hearing loss in hearing-impaired patients can be assessed by inventory questionnaires. The abbreviated profile of hearing aid benefit (APHAB) measures subjective hearing loss in four typical hearing situations (subscales). It is used to fit hearing aids in patients with statutory insurance in Germany. In addition, the unaided APHAB ( $\mathrm{APHAB}_{\mathrm{u}}$ ) can be used as a primary diagnostic instrument in audiology. There are no published data regarding the sensitivity and specificity of the unaided $\mathrm{APHAB}_{\mathrm{u}}$. Therefore, we investigated these parameters for detecting hearing loss of at least $25 \mathrm{~dB}$ at any frequency between 0.5 and $8.0 \mathrm{kHz}$. We used the $\mathrm{APHAB}_{\mathrm{u}}$ to determine hearing loss in 245 subjects aged 50 years and older
\end{abstract}

Jan Löhler

loehler@hno-aertze.de

1 Scientific Institute for Applied ENT-Research of the German Professional Association of ENT-Surgeons, Bad Bramstedt, Germany

2 Wissenschaftliches Institut für angewandte HNO-Heilkunde (WIAHNO) des Deutschen Berufsverbandes der HNO-Ärzte e. V., Maienbeeck 1, 24576 Bad Bramstedt, Germany

3 Department of ENT-Surgery, University Hospital Schleswig-Holstein, Campus Luebeck, Luebeck, Germany

4 Klinik für HNO-Heilkunde, Universitätsklinikum Schleswig-Holstein, Campus Lübeck, Luebeck, Germany

5 Institute for Medical Statistics, Informatics and Documentations, University Hospital Jena, Jena, Germany

6 Section of Phoniatrics and Pedaudiology in the Department of ENT-Surgery, University Hospital of Schleswig-Holstein, Campus Luebeck, Luebeck, Germany

7 Sektion für Phoniatrie und Pädaudiologie in der Klinik für Hals-Nasen-Ohrenheilkunde, Universitätsklinikum Schleswig-Holstein, Campus Lübeck, Luebeck, Germany without any reported disease of the ears. Due to incomplete answering of the APHAB form, 55 subjects have been excluded. We also measured the pure-tone thresholds by air conduction for all octave frequencies between 0.5 and $8 \mathrm{kHz}$. Receiver operating characteristic (ROC) curves and the Youden Index were used to determine the diagnostic value of the $\mathrm{APHAB}_{u}$, particularly sensitivity and specificity, in three different ways: (1) separately for ease of communication $\left(\mathrm{EC}_{\mathrm{u}}\right)$, background noise $\left(\mathrm{BN}_{\mathrm{u}}\right)$, and hearing with reverberation $\left(\mathrm{RV}_{\mathrm{u}}\right)$ subscales; (2) with the mean value of $\mathrm{EC}_{\mathrm{u}}, \mathrm{BN}_{\mathrm{u}}$, and $\mathrm{RV}_{\mathrm{u}}$; and (3) with a logistic regression model. The area under the ROC curve was lower for BN only (0.83) and nearly equal for all other methods (0.87-0.89). Depending on how we performed the analyses, the sensitivity of the $\mathrm{APHAB}_{\mathrm{u}}$ was $0.70-0.84$ (single subscales), 0.76 (mean value of $\mathrm{EC}_{\mathrm{u}}, \mathrm{BN}_{\mathrm{u}}$, and $\mathrm{RV}_{\mathrm{u}}$ ), or 0.85 (logistic regression model). The specificity was 0.79 0.95. The use of single $\mathrm{APHAB}_{\mathrm{u}}$ subscales for determining the sensitivity and specificity of the $\mathrm{APHAB}_{u}$ due to confusing results. In comparison, the use of the mean value of $\mathrm{EC}_{\mathrm{u}}, \mathrm{BN}_{\mathrm{u}}$, and $\mathrm{RV}_{\mathrm{u}}$ and the use of the logistic regression model due to equal values in the ROC curves but a higher sensitivity in the logistic regression model. Therefore, we would recommend the last method for determining the sensitivity and specificity of the $\mathrm{APHAB}_{\mathrm{u}}$.

Keywords Abbreviated profile of hearing aid benefit . $\mathrm{APHAB} \cdot \mathrm{APHAB}_{\mathrm{u}} \cdot$ Inventory $\cdot$ Questionnaire $\cdot$ Hearing loss $\cdot$ Hearing aid fitting $\cdot$ Sensitivity $\cdot$ Specificity $\cdot$

Diagnostic value 


\section{Introduction}

Grades of hearing loss are objectively measured by puretone and speech audiometry while self-reporting questionnaires can be used to measure subjective hearing impairment. Recently, the abbreviated profile of hearing aid benefit (APHAB), developed by Cox and Alexander [1, 2], has become an important audiological tool in Germany $[3,4]$, and it is currently the most commonly used diagnostic inventory for patients with statutory insurance in this country. There are no discernible differences between the original United States APHAB and the German adaptation $[5,6]$.

The APHAB comprises 24 single questions divided into four subscales that measure hearing loss in everyday hearing situations. The ease of communication (EC) scale examines basic hearing situations without ambient noise in a quiet environment, the background noise (BN) scale examines hearing situations with background noise, the reverberation (RV) scale investigates hearing situations in large spaces with echoes, and the aversiveness (AV) scale measures the perception of loud sound events.

Löhler et al. [7] recently demonstrated that there is an association between hearing loss in the $0.5-4.0 \mathrm{kHz}$ octave frequencies and unaided APHAB scores $\left(\mathrm{APHAB}_{\mathrm{u}}\right)$ in the $\mathrm{EC}$ and $\mathrm{RV}$ subscales. In contrast, they did not find any association between individual hearing loss typified to standard audiograms introduced by [8] and $\mathrm{APHAB}_{\mathrm{u}}$ scores in any subscale [9]. Moreover, they found that the majority of respondents answered most questions; those few questions (Question numbers 11, 18, and 21) that were answered less frequently may have been less relevant to everyday situations [10]. Finally, Löhler et al. [11] investigated associations between $\mathrm{APHAB}_{\mathrm{u}}$ scores and hearing loss at all octave frequencies between 0.5 and $8 \mathrm{kHz}$. Moreover, they investigated all of the subscales in 5\% steps and $5 \mathrm{~dB}$ level steps were investigated [11]. Löhler et al.'s multiple investigations demonstrated a relatively high association between hearing loss and $\mathrm{APHAB}_{\mathrm{u}}$ scores for the EC and RV subscales, but not for the BN subscale. As in speech audiometry, this is probably due to the ability of individuals to learn how to compensate for $\mathrm{BN}$. Hearing with RV is rarer than problems with $\mathrm{BN}$; thus, there are fewer opportunities for individuals to experience RV and develop ways to compensate for it. Moreover, hearing problems in normal, low-noise conditions (EC) generally affect only individuals with severe hearing loss, with, again, fewer opportunities to learn how to compensate. The AV subscale score does appear to be negatively associated with hearing loss $[7,10]$. The three subscales $\mathrm{EC}, \mathrm{BN}$, and RV assess understanding in different situations. In general, increasing levels of hearing loss are associated with increasing scores in the specific subscale and opposite, as has been demonstrated [7, 9]. In contrast, the AV subscale, detecting how noisy situations were misperceived (respectively, the aversiveness of sounds), is characterized by decreasing $\mathrm{APHAB}_{\mathrm{u}}$ values correlated to increasing $\mathrm{dB}$ values of hearing loss [7].

To the best of our knowledge, no published studies have addressed the sensitivity and specificity of the APHAB for detecting a defined hearing loss. This lack of data is typical of most inventories [12]. Because of the important role that the APHAB plays in healthcare in Germany, the aim of the present study was to measure the sensitivity and specificity of the APHAB for detecting a hearing loss of at least $25 \mathrm{~dB}$ in one or more of the octave frequencies between 0.5 and $8.0 \mathrm{kHz}$ by the following three methods: (1) separate calculations for the $\mathrm{EC}_{\mathrm{u}}, \mathrm{BN}_{\mathrm{u}}$, and $\mathrm{RV}_{\mathrm{u}}$ subscales; (2) calculation of the mean of the $\mathrm{EC}_{\mathrm{u}}, \mathrm{BN}_{\mathrm{u}}$, and $\mathrm{RV}_{\mathrm{u}}$ subscales; and (3) a logistic regression model for the $\mathrm{EC}_{\mathrm{u}}, \mathrm{BN}_{\mathrm{u}}$, and $\mathrm{RV}_{\mathrm{u}}$ subscales. Due to the mentioned effect of the opposite character of the AV subscale (measuring the aversiveness of loud situations), it is not rational to include the AV subscale for determining the sensitivity and specificity of the $\mathrm{APHAB}_{\mathrm{u}}$. The high variance of individual compensating effects will limit the use of BN subscale for the detection of sensitivity and specificity as well. Therefore, it may be of benefit to focus on the EC and RV subscales within our investigation.

With the values of specificity and sensitivity, the last missing main characteristic of the APHAB will be described. Together with the known attributes [7, 9-11] the results of individual APHAB scores could be well interpreted on the background of anamnesis and the data of pure-tone and speech audiometry to evaluate a specific hearing loss.

\section{Methods}

In Germany, an APHAB database has been established several years ago [13]. Between 1 May 2016 and 30 June 2016, we administered the $\mathrm{APHAB}_{\mathrm{u}}$ to 245 subjects aged 50 years and older who had no actual or reported disease of the ears or hearing impairment. Thus, we used the APHAB as a primary diagnostic tool for hearing loss. In addition, we measured and recorded the pure-tone thresholds of the participants at all octave frequencies between 0.5 and $8.0 \mathrm{kHz}$ by air conduction. The database did not include a record of patients who had a difference in hearing loss of $>60 \mathrm{~dB}$ in comparisons of air conduction for both ears at frequencies at $0.5,1.0$, and $2.0 \mathrm{kHz}$, based on the three-frequency table [5, $6]$. We excluded these patients to avoid the influence of compensatory effects in cases of severe hearing loss asymmetry. In addition, this should make our results comparable to other APHAB investigations which used the same condition [5-7, 9-11]. We collected data both via an online questionnaire method and from traditional paper-and-pencil questionnaires 
and later database entering via internet-based access. All data were stored on a central server. The subjects' participation in data storage was voluntary. The Ethics Commission of the Schleswig-Holstein Medical Association and the state data protection officer approved the research methods.

We used receiver operating characteristic (ROC) curves $[14,15]$ to evaluate the sensitivity and specificity of the $\mathrm{APHAB}_{\mathrm{u}}$ to detect a hearing loss of $25 \mathrm{~dB}$ in at least one of the octave frequencies between 0.5 and $8.0 \mathrm{kHz}$ in any ear. Using $5 \mathrm{~dB}$ steps in pure-tone thresholds, this will lead to the same results as using a cutoff value for hearing loss of more than $20 \mathrm{~dB}$. Logistic regression was used to construct the ROC curves. We determined the diagnostic value of the $\mathrm{APHAB}_{u}$ by the area under the ROC curve (AUC) with $95 \%$ confidence intervals. The threshold of the $\mathrm{APHAB}_{u}$ was identified with the Youden Index [16] and calculated by sensitivity + specificity -1 .

In accordance with the aim of our study, we analyzed all of the data to determine the sensitivity and specificity of the $\mathrm{APHAB}_{\mathrm{u}}$ by means of the following three methods:

1. We determined the optimal cutoff values for detecting hearing loss by considering $\mathrm{EC}_{\mathrm{u}}, \mathrm{BN}_{\mathrm{u}}$, and $\mathrm{RV}_{\mathrm{u}}$ individually.

2. We determined the optimal cutoff value using the arithmetic mean value of the unaided $\mathrm{EC}, \mathrm{BN}$, and $\mathrm{RV}$ subscales:

$$
\bar{x}=\frac{\mathrm{EC}_{\mathrm{u}}+\mathrm{BN}_{\mathrm{u}}+\mathrm{RV}_{\mathrm{u}}}{3} .
$$

3. We determined the probability (cutoff) for the unaided EC and RV subscales with a logistic transforming regression analysis mode using a logistic regression model with random effects [17]. The following equation shows the fixed effects for the model at hand. Here $p$ denotes the probability of hearing loss in any frequency ranging from 0.5 to $8.0 \mathrm{kHz}$ :

$\ln \left(\frac{p}{1-p}\right)=a+b \mathrm{EC}_{\mathrm{u}}+c \mathrm{RV}_{\mathrm{u}}$.
The hearing loss result of the audiogram was the dependent variable and the $\mathrm{APHAB}_{\mathrm{u}}$ scores were the independent variables. Gender and site of hearing loss were additional independent variables. The choice of a random effect model serves two purposes. One, we are able to model variability between patients and second we are able to take the paired data structure into account (left vs. right ear). Calculations were performed with SAS software version 9.4, PROC GLIMMIX (Table 1).

\section{Results}

\section{General characteristics of the study participants}

The average age of all 245 participants was 58.0 years and the median age was 59.0 years. One hundred and thirty-three of the subjects were men $(54.3 \%$, average age $58.7 \pm 12.4$ years) while one hundred and twelve were women $(45.7 \%$, average age $57.0 \pm 12.5$ years). Fortythree of the participants $(17.6 \%)$ had normal thresholds (maximum hearing loss of $20 \mathrm{~dB}$ in one or more octave frequencies between 0.5 and $8.0 \mathrm{kHz}$ ). Fifty-five subjects (22.4\%) did not answer all of the APHAB questions; this left 190 full data sets for analysis in this study. $\mathrm{APHAB}_{\mathrm{u}}$ values were independent of ear side and gender. Table 2 demonstrates the mean $\mathrm{APHAB}_{\mathrm{u}}$ values for all subscales and belonging standard deviations. Table 3 shows the mean hearing losses and standard deviations for all frequencies, groups of hearing loss (without and with hearing loss), and the side of the ears.

\section{$\mathrm{APHAB}_{\mathrm{u}}$ sensitivity and specificity according to the three models}

Table 4 contains the results of our Youden Index and ROC curve analyses of the optimal cutoff points for the $\mathrm{EC}_{\mathrm{u}}$, $\mathrm{BN}_{\mathrm{u}}$, and $\mathrm{RV}_{\mathrm{u}}$ scores and the ability of the average score of these subscales (Eq. 1) to detect any hearing loss of $\geq 25 \mathrm{~dB}$

Table 1 Three-frequency table to define the degree of hearing impairment Adapted from [5, 6]

\begin{tabular}{lllll}
\hline \multicolumn{5}{c}{ Hearing loss at $2.0 \mathrm{kHz}$} \\
\cline { 2 - 5 } & $<20 \mathrm{~dB}$ & $20-35 \mathrm{~dB}$ & $40-55 \mathrm{~dB}$ & $60-80 \mathrm{~dB}$ \\
\hline \multicolumn{2}{l}{ Total hearing loss at 0.5 and $1.0 \mathrm{kHz}$} & & & Moderate-profound \\
$0-35 \mathrm{~dB}$ & None & Slight & Moderate & Profound \\
$40-75 \mathrm{~dB}$ & Slight & Slight & Moderate & Moderate-profound \\
$80-115 \mathrm{~dB}$ & Moderate & Moderate & Moderate & Moderate-profound \\
$120-160 \mathrm{~dB}$ & Moderate-profound & Moderate-profound & Moderate-profound & Moderate-profound \\
$>160 \mathrm{~dB}$ & Profound & Profound & Profound & Profound \\
\hline
\end{tabular}

Findings from the sound audiogram of the inferior ear measured in 5-dB steps. Subjects with a difference of $>60 \mathrm{~dB}$ of hearing loss between the left and right ears were initially excluded from the database 
Table 2 Mean $\mathrm{APHAB}_{\mathrm{u}}$ values and standard deviation for each subscale for all groups

\begin{tabular}{lllcccc}
\hline $\begin{array}{l}\mathrm{APHAB}_{\mathrm{u}} \\
\text { subscale }\end{array}$ & Mean all subjects & $\begin{array}{l}\text { Standard } \\
\text { deviation }\end{array}$ & $\begin{array}{l}\text { Mean group } \\
\text { normal hearing }\end{array}$ & $\begin{array}{l}\text { Standard } \\
\text { deviation }\end{array}$ & $\begin{array}{l}\text { Mean group } \\
\text { hearing loss }\end{array}$ & $\begin{array}{l}\text { Standard } \\
\text { deviation }\end{array}$ \\
\hline EC & 23.28 & 24.29 & 4.98 & 9.77 & 27.34 & 24.68 \\
$\mathrm{BN}$ & 37.75 & 25.57 & 15.72 & 15.05 & 42.79 & 24.82 \\
$\mathrm{RV}$ & 32.71 & 25.50 & 8.73 & 7.94 & 38.56 & 24.88 \\
$\mathrm{AV}$ & 37.89 & 25.48 & 36.00 & 25.85 & 38.29 & 25.45 \\
\hline
\end{tabular}

Table 3 Mean hearing loss vs. ear site, frequency, and patient group

\begin{tabular}{|c|c|c|c|c|}
\hline Group & Side of ear & $\begin{array}{l}\text { fre- } \\
\text { quency } \\
(\mathrm{kHz})\end{array}$ & $\begin{array}{l}\text { Mean hear- } \\
\text { ing loss (dB) }\end{array}$ & $\begin{array}{l}\text { Standard } \\
\text { deviation }\end{array}$ \\
\hline \multirow[t]{10}{*}{ Normal hearing } & \multirow[t]{5}{*}{ Left } & 0.5 & 10.73 & 4.69 \\
\hline & & 1.0 & 9.39 & 5.83 \\
\hline & & 2.0 & 11.10 & 5.76 \\
\hline & & 4.0 & 12.93 & 6.12 \\
\hline & & 8.0 & 11.34 & 6.89 \\
\hline & \multirow[t]{5}{*}{ Right } & 0.5 & 10.49 & 5.34 \\
\hline & & 1.0 & 9.76 & 6.02 \\
\hline & & 2.0 & 12.20 & 5.71 \\
\hline & & 4.0 & 12.93 & 5.47 \\
\hline & & 8.0 & 13.54 & 6.25 \\
\hline \multirow[t]{10}{*}{ With hearing loss } & \multirow[t]{5}{*}{ Left } & 0.5 & 24.28 & 13.74 \\
\hline & & 1.0 & 26.06 & 15.60 \\
\hline & & 2.0 & 35.66 & 19.81 \\
\hline & & 4.0 & 50.95 & 21.16 \\
\hline & & 8.0 & 55.16 & 20.93 \\
\hline & \multirow[t]{5}{*}{ Right } & 0.5 & 23.39 & 12.72 \\
\hline & & 1.0 & 26.28 & 14.68 \\
\hline & & 2.0 & 34.61 & 18.88 \\
\hline & & 4.0 & 47.57 & 21.00 \\
\hline & & 8.0 & 51.68 & 21.32 \\
\hline
\end{tabular}

in one or more of the octave frequencies between 0.5 and $8.0 \mathrm{kHz}$. The ROC curves for $\mathrm{RV}_{\mathrm{u}}$ only; for the mean value of $\mathrm{EC}_{\mathrm{u}}, \mathrm{BN}_{\mathrm{u}}$, and $\mathrm{RV}_{\mathrm{u}}$; and for the logistic regression model are presented in Figs. 1, 2, and 3. The probability (cutoff) determined by the Youden Index and ROC curve for logistic regression (Eq. 2a) was 0.63 (Table 4). We used this value in a multivariate mixed linear model for fixed effects based on the values of the constants $a, b$, and $c$ in Eq. (2a) (Table 5):

$\ln \left(\frac{p}{1-p}\right)=-0.82+0.06 * \mathrm{EC}_{\mathrm{u}}+0.09 * \mathrm{RV}_{\mathrm{u}}$.

Because of the natural logarithmic scale of the calculated values in the second column of Table 5, the influence of $R V_{u}$ was twice as large as that of $\mathrm{EC}_{\mathrm{u}}$.
Table 4 Diagnostic value of (1) individual $\mathrm{APHAB}_{\mathrm{u}}$ subscales; (2) average value of $\mathrm{EC}_{\mathrm{u}}, \mathrm{BN}_{\mathrm{u}}$, and $\mathrm{RV}_{\mathrm{u}}$ subscales $(\bar{x})$; and (3) logistic regression model

\begin{tabular}{llllll}
\hline $\mathrm{APHAB}_{\mathrm{u}}$ subscale & $\mathrm{EC}_{\mathrm{u}}$ & $\mathrm{BN}_{\mathrm{u}}$ & $\mathrm{RV}_{\mathrm{u}}$ & $\bar{x}$ & Logistic model \\
\hline Cutoff value & 0.10 & 0.23 & 0.12 & 0.15 & 0.63 \\
Area under curve & 0.88 & 0.83 & 0.88 & 0.87 & 0.89 \\
$\quad$ 95\% CI & & & & & \\
$\quad$ Lower & 0.82 & 0.76 & 0.83 & 0.81 & 0.84 \\
$\quad$ Upper & 0.93 & 0.89 & 0.93 & 0.93 & 0.94 \\
Sensitivity & 0.70 & 0.75 & 0.84 & 0.76 & 0.85 \\
95\% CI & & & & & \\
$\quad$ Lower & 0.63 & 0.68 & 0.77 & 0.68 & 0.79 \\
$\quad$ Upper & 0.76 & 0.81 & 0.89 & 0.82 & 0.90 \\
Specificity & 0.95 & 0.79 & 0.81 & 0.85 & 0.81 \\
95\% CI & & & & & \\
$\quad$ Lower & 0.84 & 0.64 & 0.65 & 0.71 & 0.65 \\
Upper & 0.99 & 0.90 & 0.91 & 0.94 & 0.91
\end{tabular}

Cutoff value: $\mathrm{APHAB}_{\mathrm{u}}$ score for the presented values of sensitivity and specificity

95\% CI 95\% confidence interval

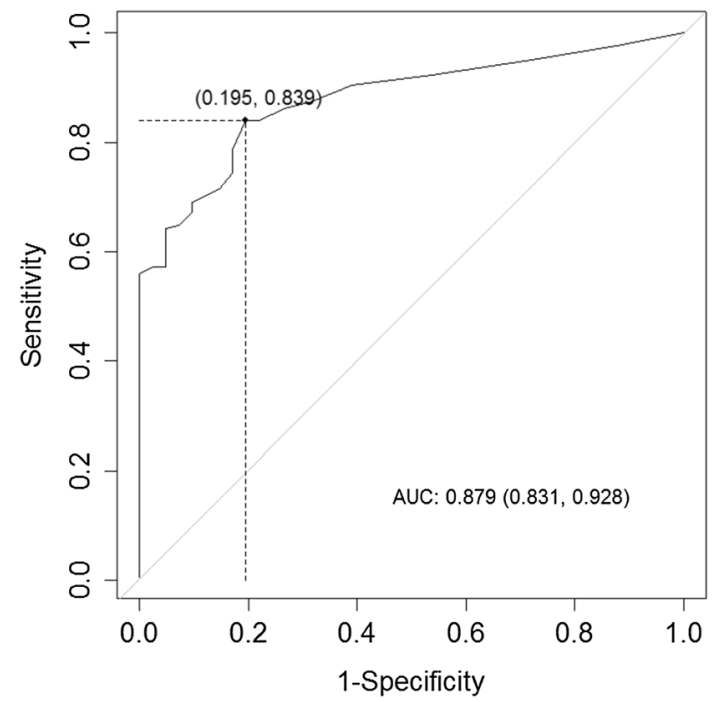

Fig. 1 ROC curve for detecting a hearing loss of $25 \mathrm{~dB}$ using the RV subscale score 


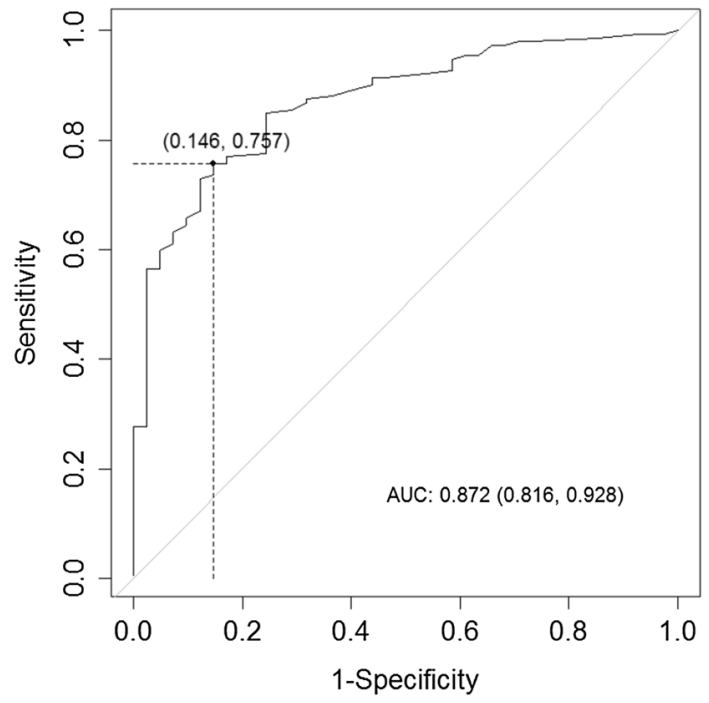

Fig. 2 ROC curve for detecting a hearing loss of $25 \mathrm{~dB}$ using the mean of the $\mathrm{EC}, \mathrm{BN}$, and $\mathrm{RV}$ scores

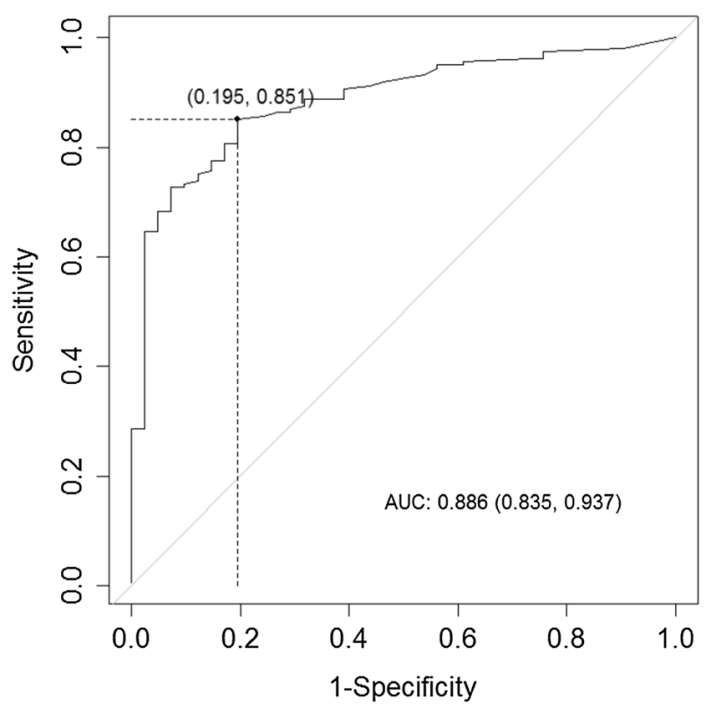

Fig. 3 ROC curve for detecting a hearing loss of $25 \mathrm{~dB}$ using the logistic regression model

Table 5 Values of constants for Eq. (2a) (logistic regression model, see text)

\begin{tabular}{lrrrr}
\hline Constant & Value & $p$ & \multicolumn{2}{l}{$\begin{array}{l}\text { 95\% confidence } \\
\text { interval }\end{array}$} \\
\cline { 3 - 5 } & & & Lower & Upper \\
\hline a. Intercept & -0.82 & 0.02 & -1.50 & -0.14 \\
b. EC & 0.06 & 0.12 & -0.01 & 0.13 \\
c. RV & 0.09 & $<0.01$ & 0.04 & 0.14 \\
\hline
\end{tabular}

\section{Discussion}

We found that neither the side of the ear nor gender influenced the $\mathrm{APHAB}_{\mathrm{u}}$ score. This finding is in concordance with those of previously published reports. The mean age of our group of participants was younger than studies that included subjects with are subsequently fitted with hearing aids $[7,9,10]$. According to previous results, the AV subscale is different for all others. Measuring the aversiveness of sounds due to very similar $\mathrm{APHAB}_{\mathrm{u}}$ scores in both investigated groups (normal hearing and with hearing loss), as demonstrated in Table 2. Using single subscales of $\mathrm{APHAB}_{\mathrm{u}}(\mathrm{EC}, \mathrm{BN}$, and RV) leads to nearly similar cutoff values for $\mathrm{EC}_{\mathrm{u}}$ and $\mathrm{RV}_{\mathrm{u}}$, and, by comparison, the cutoff score for $\mathrm{BN}_{\mathrm{u}}$ was even higher (Table 4). This may be explained by more widespread individual compensation abilities for hearing loss, as shown previously [9, 10]. In addition, the cutoff vaulue for the average model (Eq. 1) due to a value (0.15) which is closer to the values of $\mathrm{EC}_{\mathrm{u}}(0.10)$ and $\mathrm{RV}_{\mathrm{u}}(0.12)$ than the $\mathrm{BN}_{\mathrm{u}}$ value $(0.23)$ by the single use of the subscales. As has been reported, $\mathrm{BN}$ subscale scores are not associated with individual hearing loss [7]. Maybe, the lower $\mathrm{APHAB}_{\mathrm{u}}$ values of the normal hearing group in EC and RV (Table 2) could support this thesis. In addition, the sensitivity using single subscales is resulting in different values around 0.70 and 0.84 , whereas the mean subscale (Eq. 1) is 0.76 . Although both models are due to values within the confidence intervals, the average model (Eq. 1) may be superior to use of the individual subscales. At least, it is simpler to use one value in sensitivity and specificity than three. This level of sensitivity and specificity is as high as that of other inventories, such as the hearing handicap inventory for the elderly screening version (HHIE-S, [18]) and the Mini-Audio-Test (MAT, [19]). Subjects in the group with false-negative results may ignore their hearing problems, or they may be able to compensate for their hearing impairment. An alternative model is the logistic regression model (Eq. 2b), which uses the constants from Table 5. This model has an even higher level of sensitivity, but its specificity is slightly lower than that of the average model (Eq. 1).

It might be surprising that a hearing loss of $25 \mathrm{~dB}$ has an influence on $\mathrm{APHAB}_{\mathrm{u}}$ scores. In fact, including $8.0 \mathrm{kHz}$ might be very strict and not used in MAT [19], and increases at least the number of healthy or sick ears. But our findings confirm previous results [7, 10]. In addition, such an influence of $8.0 \mathrm{kHz}$ has been detected for the HHIE-S as well [20]. In contrast to the APHAB, the HHIE-S and the MAT are developed for screening use only. The APHAB is too large to play an important role in screening. Nevertheless, sensitivity and specificity are required characteristics for inventories in general [12]. 
At present, some rather difficult methods in conjunction with the APHAB to measure the quality of hearing aid fitting in patients with statutory insurance are used in Germany [3, 4]. They calculate relations of the differences of subscales to their means which can due to some problems in the result by arithmetic reasons. Of course, these methods are based on the difference of two APHAB forms, before and after hearing aid fitting. But going forward, it may be of benefit to patient and clinicians to instead use modified Eqs. (1) or (2a) for quality measurement of hearing aid fitting as well. However, further research is required to validate our results with these models. These models may be of particular benefit in cases in which the $\mathrm{APHAB}_{\mathrm{u}}$ is being used as a screening inventory or as a primary audiological diagnostic method. Use of the logistic regression model to determine the diagnostic value of the APHAB ${ }_{u}$ may be justified by the weighted influence of the RV subscale. Recent investigations have found that the likelihood of individual compensatory effects is highest for BN and lowest for RV and that the influence of the EC subscale is limited to cases with increased hearing loss $[7,10]$. In summary, our determination of the sensitivity and specificity of the $\mathrm{APHAB}_{\mathrm{u}}$ adds to the knowledge of this widely used inventory in Germany. We suggest that future studies investigate the values of these parameters separately for each frequency. Together with the recently published percentile distribution curves and box plots of the unaided and aided APHAB and the resulting benefit [21] and together with the knowledge of mutual dependencies of $\mathrm{APHAB}_{\mathrm{u}}$ scores, pure-tone thresholds, and speech-audiometric results, it is well possible to interpret an individual hearing loss.

\section{Compliance with ethical standards}

Conflict of interest None of the authors have any conflicts of interest.

Source of funding None of the authors have any sources of funding to disclose.

Ethical approval This research involved human participants. Participation in the study and subjects' data storage were voluntary. The Ethics Commission of the Schleswig-Holstein Medical Association and the state data protection officer approved the research methods.

Informed consent All of the participants provided written informed consent prior to inclusion in the study. All of the participants signed a declaration of informed consent for storage of all of their anonymized data.

Open Access This article is distributed under the terms of the Creative Commons Attribution 4.0 International License (http://creativecommons.org/licenses/by/4.0/), which permits unrestricted use, distribution, and reproduction in any medium, provided you give appropriate credit to the original author(s) and the source, provide a link to the Creative Commons license, and indicate if changes were made.

\section{References}

1. Cox RM, Alexander GC (1995) The abbreviated profile of hearing aid benefit. Ear Hear 16:176-186

2. Johnson JA, Cox RM, Alexander GC (2010) Development of APHAB norms for WDRC hearing aids and comparisons with original norms. Ear Hear 3:47-55

3. Löhler J, Akcicek B, Wollenberg B et al (2014) Implementation of the new quality assurance agreement for the fitting of hearing aids in daily practice. Part 1 : new regulations pertaining to hearing aid fitting. HNO 62:605-612

4. Löhler J, Akcicek B, Wollenberg B et al (2014) Implementation of the new quality assurance agreement for the fitting of hearing aids in daily practice. Part 2: new diagnostic aspects of speech audiometry. HNO 62:667-682

5. Löhler J, Frohburg R, Moser L (2010) The use of the German APHAB for quality control in hearing aid fitting in an ENT-office. Comparison of our results with the given US-norm. Laryngo Rhino Otol 89:737-744

6. Löhler J, Moser L, Heinrich D et al (2012) Results of clinical use of the German version of the APHAB. HNO 60:626-636

7. Löhler J, Akcicek B, Wollenberg B et al (2016) The influence of frequency-dependent hearing loss to unaided APHAB scores. Eur Arch Otorhinolaryngol 273:3587-3593

8. Lehnardt E, Laszig R (2009) Praxis der Audiometrie. Thieme, Stuttgart

9. Löhler J, Akcicek B, Wollenberg B et al (2016) The influence of hearing loss represented by standard audiogram types to unaided APHAB scores. Laryngo Rhino Otol 95:540-545

10. Löhler J, Wollenberg B, Schlattmann P et al (2017) Associations between the probabilities of frequency-specific hearing loss and unaided APHAB scores. Eur Arch Otolaryngol 274:1345-1349

11. Löhler J, Akcicek B, Wollenberg B et al (2016) Distribution and scattering of APHAB answers before and after hearing aid fitting. Laryngo Rhino Otol 95:768-773

12. Miller S, Kühn D, Ptok M (2013) Assessment inventories for hearing aid outcome. Laryngo Rhino Otol 92:80-89

13. Löhler J, Akcicek B, Kappe T, Schlattmann P, Wollenberg B, Schönweiler R (2014) Development and use of an APHAB database. HNO 62:735-745

14. Greiner M (2003) Serodiagnostische tests. Springer, Berlin

15. Pepe M (2003) The statistical evaluation of medical tests for classification and prediction. Oxford University Press, Oxford

16. Youden WJ (1950) Index for rating diagnostic tests. Cancer 3:32-35

17. Fahrmeir L, Tutz G (2001) Multivariate statistical modeling based on generalized linear models. Springer, Heidelberg

18. Ventry IM, Weinstein BE (1982) The hearing handicap inventory for the elderly: a new tool. Ear Hear 3:128-134

19. Löhler J, Schlattmann P, Walther LE (2013) The Mini-Audio-Test (MAT). Screening inventory for hearing loss starting at the age of 50. Otol Rhino Laryngol 92:815-822

20. Calviti KC, Pereira LD (2009) Sensitivity, specificity and predictive values of hearing loss to different audiometric mean values. Braz J Otorhinolaryngol 75:794-800

21. Löhler J, Wollenberg B, Schönweiler R (2017) APHAB scores for individual assessment of the benefit of hearing aid fitting. HNO. doi:10.1007/s00106-017-0350-z 